\title{
RESENHA De guri a cabra-macho: masculinidades no Brasil
}

Esmael Alves de Oliveira ${ }^{1}$ Universidade Federal da Grande Dourados

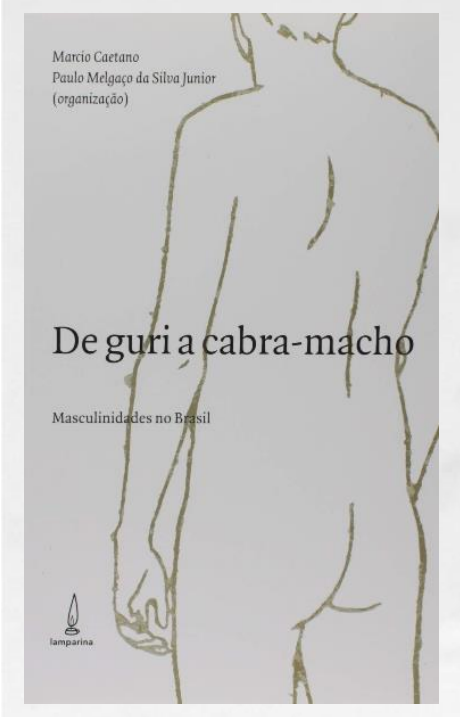

CAETANO, Marcio; SILVA JUNIOR, Paulo Melgaço da. De guri a cabra-macho: masculinidades no Brasil. Rio de Janeiro: Lamparina, 2018. 23op. 
$\mathrm{O}$ rganizado pelos pesquisadores Marcio Caetano e Paulo Melgaço da Silva Junior, o livro De guri a cabra-macho: masculinidades no Brasil traz uma importante contribuição ao campo de estudos sobre masculinidades. Enquanto campo de estudos que vem se consolidando pelo menos desde os anos 1980, no Brasil o tema das masculinidades tem alcançado nas últimas décadas um interesse crescente - o que se demonstra pelos inúmeros livros, coletâneas, dossiês e artigos sobre o tema (ARILHA, UNBEHAUM e MEDRADO, 1998; SCHPUN, 2004; THÜRLER e MEDRADO, 2020).

É nesse quadro que se entende a importância da obra. Ao longo dos 11 capítulos, autores e autoras pertencentes a diferentes universidades públicas do país, ancorados em uma perspectiva transdisciplinar, privilegiando uma diversidade de temas e problemas de pesquisa e articulando diferentes métodos e teorias, nos ajudam a compreender as masculinidades como um complexo artefato históricocultural atravessado por inúmeros marcadores sociais de diferença.

É nesse movimento de retomada de pressupostos do campo e de ampliação da crítica que Benedito Medrado e Jorge Lyra elaboram o prefácio da obra. De acordo com os pesquisadores, se "não podemos dizer que este é um tema novo em nosso país" (2018: 7), por outro lado há que se reconhecer que não se trata ainda de "um objeto ampla e profundamente explorado" (idem).

Na apresentação, Marcio Caetano e Paulo Melgaço da Silva Junior ressaltam a importância política de maio de 1968, na França, e suas repercussões no processo de desnaturalização e desestabilização das masculinidades. Utilizando-se da metáfora de Exu, divindade iorubá responsável pelos caminhos, os autores nos interpelam para a necessidade de compreensão das trajetórias e "des-caminhos" em torno das masculinidades para que isso resulte, de fato, no questionamento "da lógica hegemônica da masculinidade" (2018:12).

No primeiro capítulo, intitulado "Essa história de ser homem: reflexões afetivo-políticas sobre masculinidades”, Marcos Nascimento, a partir de memórias pessoais, elabora uma instigante genealogia "acadêmica, profissional e de ativismo" em torno das masculinidades no Brasil e no mundo nos últimos trinta anos. A partir desse cenário, a masculinidade passa a ser problematizada a partir de quatro eixos de análise: saúde, educação, paternidade e homossexualidade/transexualidade. Nas palavras do autor, "pensar "essa história de ser homem' é pensar sobre que projeto de sociedade queremos" (2018: 25).

No capítulo dois, "Transmasculinidades, transformações corporais e saúde: algumas transformações antropológicas", Camilo Braz e Érica Renata de Souza discutem o tema das transmasculinidades a partir de três tópicos: transformações corporais, masculinidade hegemônica e políticas de saúde, (d)enunciando os inúmeros paradoxos que cercam as lutas em torno de visibilidade e acesso a direitos por parte desta população. Não por acaso, concluem: "as políticas públicas para a saúde de homens trans implicam numa especificidade para além da 'transexualidade' como uma categoria genérica para homens e mulheres trans” (2018: 39).

Em "experiência estética e desestabilizações das masculinidades no teatro brasileiro moderno e contemporâneo”, Elton Bruno Soares de Siqueira e Marcelo Miranda partem da seguinte indagação: "Como o teatro brasileiro expressa indí- 
cios de uma crise dos valores masculinos hegemônicos que contribuem para desestabilizar os lugares das masculinidades hegemônicas e das masculinidades subalternas?" (2018: 43). Por meio da análise das obras dramatúrgicas de Nelson Rodrigues, Plínio Marcos e Newton Moreno, constata-se como elas contribuíram e continuam a contribuir "para revelar a crise dos valores masculinos burgueses" (2018: 61).

Fernando Seffner e Cláudio Nunes, no capítulo "O corpo a ser estudado, a pedagoga e a classe de alunos: encenando reiterações da masculinidade heterossexual”, estabelecem uma correlação entre a prática de uma professora de ensino religioso em uma escola pública e uma Drag Queen em um clube de sexo destinado ao público LGBT. A partir da análise empreendida, Seffner e Nunes detectam não apenas "que há pedagogias do gênero e da sexualidade em funcionamento nos dois locais, e que se parecem" (2018: 66), mas também o quanto a força da heteronormatividade está presente em ambos os contextos.

Em “'Não tem nenhum viado aqui': a construção de masculinidades em uma unidade socioeducativa no município do Rio de Janeiro”, Jonas Alves da Silva Junior e Maria de Lourdes Ramos da Silva apresentam sua pesquisa de campo junto a uma unidade socioeducativa localizada na baixada fluminense. A partir dessa experiência, problematizam o quanto as masculinidades de jovens cumprindo medidas socioeducativas são forjadas em moldes sexistas, hierarquizados e violentos. Não por acaso, afirmam que "os vetores que delimitam a masculinidade padrão são a heterossexualidade e a dominação" (2018: 97).

No capítulo seis, "Masculinidades e práticas sexuais na Amazônia Oriental: notas de campo com base em uma experiência etnográfica”, José Sena Filho problematiza a produção das masculinidades tomando como ponto de partida seu trabalho de campo no município paraense de Bragança, ao relatar um conflito instaurado em um contexto de interação pós-festa ("after party"), após uma troca afetivo-sexual entre um interlocutor assumidamente gay afeminado e um parceiro autodefinido como heterossexual, decorrente do fato de este último ter retirado o preservativo no meio do intercurso sexual sem o consentimento do parceiro. Para o autor, isso seria reflexo de "uma correlação entre exercício de masculinidade e a falta de cuidado com a saúde sexual" (2018: 123).

Megg Rayara de Oliveira, no capítulo intitulado "Seguindo os passos 'delicados' de gays afeminados, viados e bichas pretas no Brasil”, demonstra como o modelo de masculinidade cis-heteronormativa está estreitamente articulado com racismo e homofobia. A autora observa que nas discussões étnico-raciais há o apagamento da diversidade de gênero e da orientação sexual e que no âmbito das discussões de gênero e diversidade sexual há o silenciamento do pertencimento racial dos sujeitos. Nesse sentido, ela chama a atenção para o quanto categorias como negro e homossexual "contribuem para naturalizar a cis heterossexualidade e a branquitude normativa” (2018: 142).

Por sua vez, em "O sacrifício de Orfeu: masculinidades negras no contexto da antinegritude em Salvador”, Osmundo Pinho (d)enuncia os limites de uma construção de negritude sustentada no heteropatriarcado. Embasado tanto em uma crítica literária quanto em dados sociodemográficos, problematiza o quanto, a partir de uma gramática de colonialidade do poder, "o homem negro, em sua luta por reconhecimento, tomaria o modelo patriarcal ocidental [...] como modelo de poder" (2018: 149).

Em “'Daí, não se ensina direito': narrativas com/sobre rapazes negros para uma educação libertadora”, Suely Aldir Messeder, Elisete Santana da Cruz França 
e Maria Nazaré Mota de Lima exploram os dados de campo de uma pesquisa realizada junto a oito jovens negros de uma escola pública da periferia de Salvador vinculados ao $3^{\circ}$ ano do ensino médio. Tomando como pressuposto que as brincadeiras "são atividades gendradas" (2018: 183), por meio de um diálogo travado em torno de "tipos de brincadeiras", as autoras puderam compreender os modos como se constrói a masculinidade entre esse segmento. Entre desenhos, lutas e performances, a produção e reforço "de uma cultura androcêntrica e heterossexista” (2018: 187).

No penúltimo capítulo, "Roda de homens negros: masculinidades, mulheres e religião", Paulo Melgaço da Silva Junior e Marcio Caetano interagem com um grupo de cinco homens negros moradores da cidade de São João do Meriti, município da Baixada Fluminense. Sentados na calçada em frente à casa de um dos participantes, "queimando uma carne" e tomando uma cerveja, Silva Junior e Caetano acessam valores, códigos, crenças e hierarquias responsáveis pela produção do artefato "homem negro viril”. Ali "ser 'negão' é a marca da heteronormativa (sic) que busca tatuar o corpo negro masculino" (2018: 201).

Por fim, em "Meninos de verdade: discursos de masculinidades na educação física infantil”, Erik Giuseppe B. Pereira e Leandro Teofilo de Brito buscam responder à indagação: "como se configuram as percepções e práticas de masculinidade nas aulas de educação física infantil?” (2018: 214). Tomando como lócus de análise as aulas de educação física em uma escola municipal de educação infantil pertencente ao cenário carioca, os autores constatam que "os corpos masculinos e femininos recebem uma construção cultural diferenciada" (2018: 221), fazendo com que "as oportunidades de se exercitarem não [sejam] as mesmas" (idem).

Cabe pontuar que os aspectos aqui destacados não inviabilizam outras leituras e análises nem esgotam a riqueza de questões presentes na obra. Como dissemos anteriormente, a qualidade dos dados empíricos, a diversidade teórica e metodológica na análise empreendida pelos/as diferentes autores e autoras e os diferentes pontos de vista sobre fenômenos e/ou problemáticas aproximadas põem em relevo que o campo das masculinidades é um campo em aberto. Dito isso, gostaria de destacar algumas questões que, no meu ponto de vista, destacam-se em De guri a cabra-macho.

Em primeiro lugar, a estreita articulação entre masculinidades e colonialidade. Se, para alguns, parece não se constituir como uma relação óbvia, é importante reiterar como o sistema colonial, ao invadir territórios, escravizar grupos, invadir corpos e submeter minorias raciais, étnicas e sexuais, instaura definitivamente a masculinidade cisheteronormativa como um dos empreendimentos intersubjetivos mais emblemáticos da "modernidade". Nela e por meio dela (da masculinidade), funda-se o terreno apropriado para a triangulação capitalística entre raça, classe e gênero (McCLINTOCK, 1995; LUGONES, 2007).

Em segundo lugar, e talvez como aspecto subsequente do anterior, problematizar o tema das masculinidades na chave dos marcadores sociais de diferença significa uma guinada interpretativa importante no modo de compreensão das masculinidades. Se a "masculinidade" está longe de se constituir como algo homogêneo e universal, pensá-la articulada a classe, raça, gênero, orientação sexual, geração, religião e região/localidade, dentre outros, implica compreendê-la não apenas como uma "rede complexa sobre a qual atuam forças externas e internas" (CAETANO, SILVA JUNIOR, 2018: 11), mas também, e talvez principalmente, como matéria que só ganha contorno num jogo de interações relacionais nunca aprioristicamente dadas (BUTLER, 2019).

Como terceiro aspecto, e não menos importante, se ao longo da década de 
1990 parecia prevalecer "uma forte concentração dos estudos sobre homens abordando a sexualidade" (GARCIA, 1998: 35), ao longo dos diferentes capítulos de De guri a cabra-macho é possível observar uma grande expansão e ampliação do campo. Assim, seja na dramaturgia, na literatura, no contexto das escolas, das instituições socioeducativas, das micropolíticas do cotidiano, o livro visibiliza uma série de deslocamentos empíricos que fazem com que o tema das masculinidades seja amplamente debatido para além de determinadas arenas disciplinares, o que resulta em um enriquecimento do debate.

Por fim, não podemos concluir nossa análise sem chamar a atenção para a importância que é dada para as "linhas de fuga". Como nos diz Gilles Deleuze (1998: 49):

Partir, se evadir, é traçar uma linha. [...] A linha de fuga é uma desterritorialização. Os franceses não sabem bem o que é isso. É claro que eles fogem como todo mundo, mas eles pensam que fugir é sair do mundo, místico ou arte, ou então alguma coisa covarde, porque se escapa dos engajamentos e das responsabilidades. Fugir não é renunciar às ações, nada mais ativo que uma fuga. É o contrário do imaginário. É também fazer fugir, não necessariamente os outros, mas fazer alguma coisa fugir, fazer um sistema vazar como se fura um cano. [...] Fugir é traçar uma linha, linhas, toda uma cartografia. Só se descobre mundos através de uma longa fuga quebrada.

O livro é uma preciosa contribuição para todos/as aqueles/as preocupados/as com as instabilidades, as dissidências, os pontos cegos, as zonas de ruptura presentes nos regimes de verdade que atravessam e constituem as masculinidades. Nesse enquadre, "ser" "cabra-macho" é materializar-se e materializar-se precariamente (BUTLER, 2019).

Recebido em 29 de agosto de 2020.

Aprovado em 13 de dezembro de 2020.

\section{Referências}

ARILHA, Margareth; UNBEHAUM, Sandra G.; MEDRADO, Benedito. Homens e masculinidades: outras palavras. São Paulo: ECOS/Ed. 34, 1998.

BUTLER, Judith. Corpos que importam. São Paulo: n-1 Edições/Crocodilo Edições, 2019.

DELEUZE, Gilles; PARNET, Claire. Diálogos. São Paulo: Editora Escuta, 1998. 
GARCIA, Sandra Mara. "Conhecer os homens a partir do gênero e para além do gênero". In: ARILHA, Margareth; UNBEHAUM, Sandra G.; MEDRADO, Benedito (orgs.). Homens e masculinidades: outras palavras. São Paulo: ECOS/Ed. 34, 1998. pp. 31-50.

LUGONES, María. Heterosexualism and the colonial/modern gender system. Hypatia, 22 (1): 186-209, 2007.

MCCLINTOCK, Anne. Imperial leather: race, gender, and sexuality in the colonial contest. London: Routledge, 1995.

THÜRLER, Djalma; MEDRADO, Benedito (orgs.). Dossiê masculinidades contemporâneas em disputa. Periódicus, 1 (13), 2020.

SCHPUN, Mônica Raisa (org.). Masculinidades. São Paulo: Boitempo; Santa Cruz do Sul: EDUNISC, 2004.

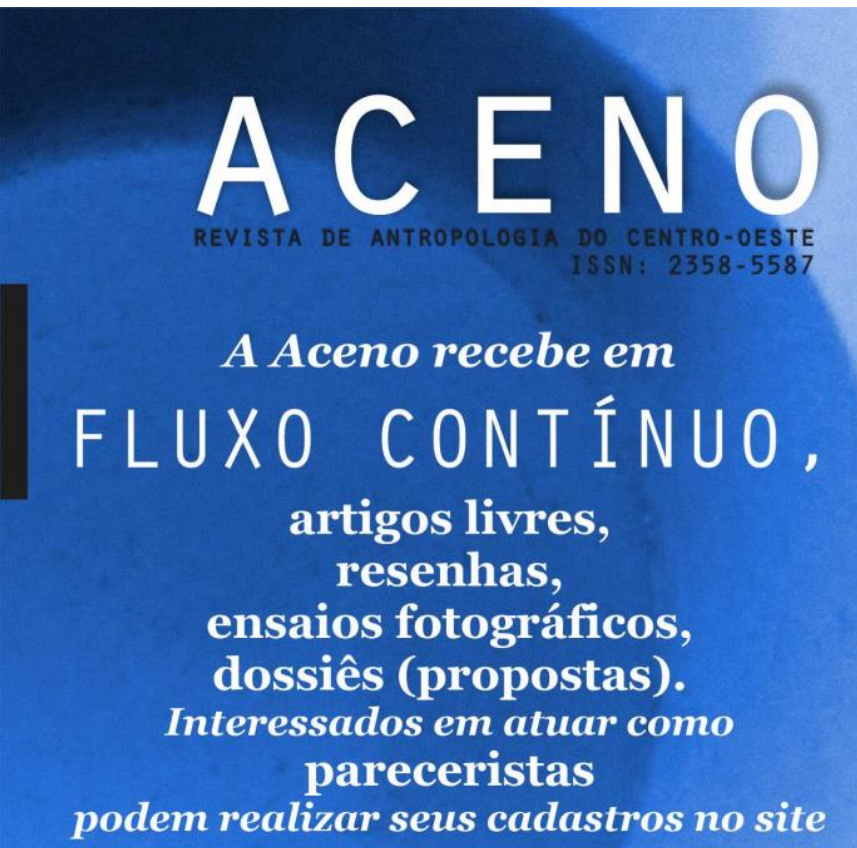

